\title{
Research on Influence Factors of Cooperatives Performance in the Agricultural Products Supply Chain Based on System Dynamics
}

\author{
Yongyue Liu' ${ }^{1}$ Xiangyu Guo ${ }^{2}$ \\ ${ }^{1}$ College of Economics and Management, Heilongjiang Bayi Agricultural University, Daqing, China \\ College of Economics and Management, Northeast Agricultural University, Harbin, China \\ Email : lyyyy6518@sina.com \\ ${ }^{2}$ College of Economics and Management, Northeast Agricultural University, Harbin, China \\ Email:guoxy@neau.edu.cn
}

\section{ARTICLE DETAILS \\ Article history: \\ Received 12 August 2016 \\ Accepted 12 December 2016 \\ Available online 20 January 2017 \\ Keywords: \\ cooperatives, agricultural \\ products supply chain, \\ performance, System Dynamics}

ABSTRACT

This paper constructs cause and effect feedback relation graph of cooperatives performance influence factors in agricultural products supply chain by utilizing system dynamics method, and searches for the external factors that affect farmer cooperatives performance, and then puts forward the countermeasures and suggestions of improving the cooperative performance on the basis of it. It enriches and deepens theoretical research theme and perspective of cooperatives development and agricultural products supply chain management issues.

\section{INTRODUCTION}

A large number of studies have shown that the low overall performance level of cooperatives in China and the low operating efficiency has seriously restricted the further development of cooperative. S. Z. Huang et al.[1], X. C. Xu et al.[2] analyzed the impact of the cooperatives ownership structure, the council structure, leader situation, internal supervision, member exit ability on the performance of cooperatives. W. H. You et al. [3] found that the cooperatives internal network relationship has greater impact on the profitability of cooperatives. Y. F. Sun et al. [4] empirically analyzed the property rights arrangements, governance and other together effect and restrict the organizational performance of cooperatives. D. H. Li et al.[5] empirically analyzed the impact of policy support, technical factors, internal management mechanisms and other aspects on cooperatives performance. The above literature can be found that most scholars have studied the influencing factors of the performance of cooperatives from the perspective of the internal governance mechanism and the internal operation activities of the organizations of the cooperatives. There are few researches about external influencing factors facing by the cooperatives in the agricultural supply chain. Based on the perspective of agricultural products supply chain, it is of great theoretical and practical value to study the influencing factors of cooperatives performance.

2. ANALYSIS ON THE INFLUENCING FACTORS OF COOPERATIVES PERFORMANCE IN AGRICULTURAL PRODUCTS SUPPLY CHAIN

A. Feedback Analysis of Market Environment Subsystem Feedback

"Fig. 1" shows the impact of the external market environment on the performance of cooperative. There are two positive feedback loops in the subsystem.

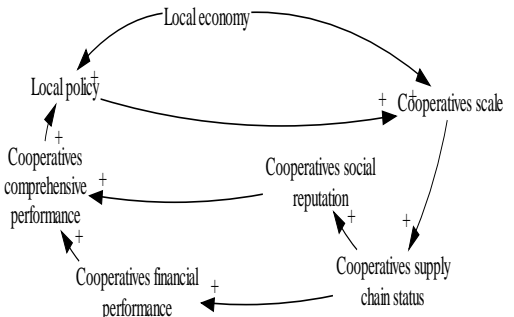

Cite this article Yongyue Liu ${ }^{1}$, Xiangyu Guo ${ }^{2}$ Research on Influence Factors of Cooperatives Performance in the Agricultural Products Supply Chain Based on System Dynamics Malaysian E Commerce Journal (MECJ) 1(2) (2017) 01-03
Figure 1. The causal feedback figure of the market environment subsystem

From the market environment subsystem cause-and-effect relation figure can be found

Expanding the scale of cooperatives is conducive to cooperatives in the agricultural products supply chain to get a higher competitive position in the market, and even become the core of the supply chain, and thus improve the social reputation of cooperatives, increase the overall performance of cooperatives; and cooperatives performance improvement in turn is conducive to continually expand the scale of cooperatives, and continuously improve the position in the supply chain. The promotion of cooperatives' competitive position in the agricultural products supply chain is beneficial to the cooperatives to obtain more right to speak when they coordinate and distribute the interests with other subjects, to increase the income of cooperatives and to improve the financial performance of cooperatives.

Local policies, regional economic and other external environment has a direct impact on expanding the scale of the cooperatives and enhancing the status in the supply chain, and the improvement of the performance level of cooperatives will also promote the local government policy, and is more conducive to the development of cooperatives.

B. Feedback Analysis of Supply Chain Logistics Management Subsystem "Fig. 2" illustrates the constraints of logistics management elements in the agricultural products supply chain on the financial performance of cooperative, which thus affect the comprehensive performance of cooperative. There are six positive feedback loops in the subsystem.

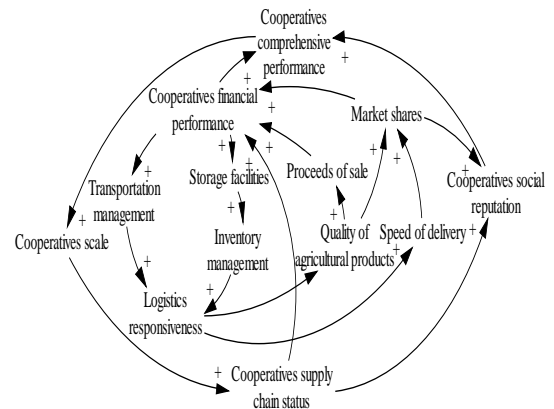


Figure 2. The causal feedback figure of supply chain logistics management subsystem.

From the supply chain logistics management subsystem cause-andeffect relation figure can be found:

The improvement of the financial performance level of the cooperatives enables the cooperatives to improve the transportation and inventory management and improve the rapid response capability of cooperatives' agricultural products logistics. This will reduce the loss of agricultural products in warehousing and transportation logistics, and ensure the quality of agricultural products, increase sales revenue and market share, improve the financial performance of cooperatives.

Increasing the level of cooperatives logistics management can also improve the delivery speed, and also help to increase market share, improve the social reputation and financial performance of cooperatives.

\section{Feedback Analysis of Supply Chain Risk Management Subsystem}

"Fig. 3" shows the mutual influence, mutual restraint relationship between the supply risk and the demand risk and the cooperative performance faced by the farmers' specialized cooperative in the agricultural products supply chain. There are four positive feedback loops in the subsystem.

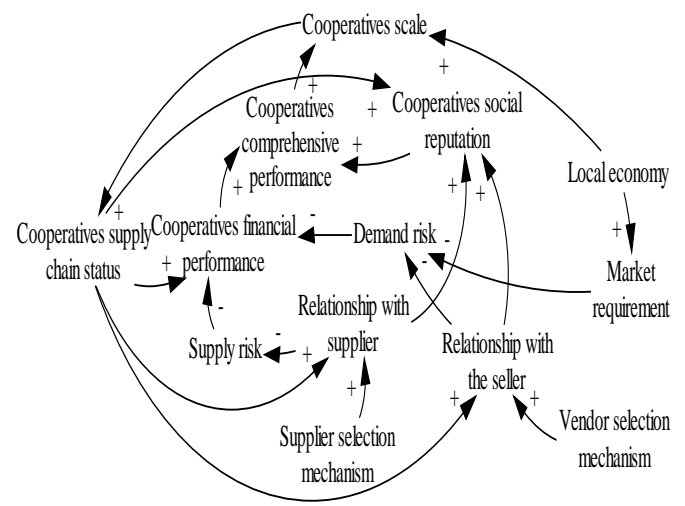

Figure 3. The causal feedback figure of supply chain risk management subsystem.

From the supply chain risk management subsystem cause-and-effect relation figure can be found:

The increase financial performance of cooperatives are conducive to the expansion of the scale of cooperatives and improve its position in the agricultural products supply chain, which is conducive to cooperatives to strengthen partnership building with upstream suppliers and downstream vendors to reduce the supply risk and demand risks. The reduction of market transaction risk in turn helps cooperatives to improve the level of financial performance. The improvement of relationship between cooperatives and partnerships can also significantly improve the social reputation of cooperatives and the overall performance of cooperatives.

\section{Feedback Analysis of Supply Chain Information Management} Subsystem

"Fig. 4" shows the impact of information management between cooperative and other stakeholders in the agricultural products supply chain on the financial performance and overall performance of cooperative. There are four positive feedback loops in the subsystem.

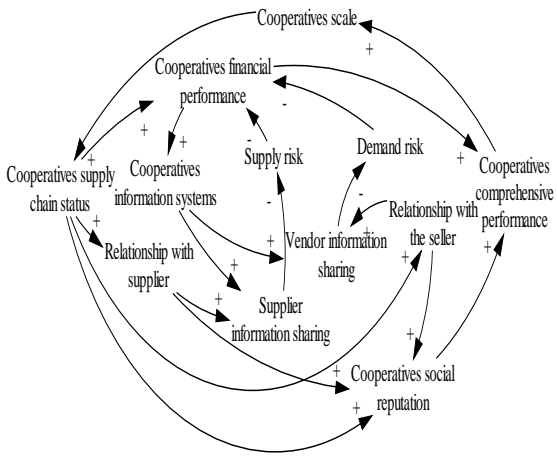

Figure 4. The causal feedback figure of supply chain information management subsystem

From the supply chain information management subsystem causeand-effect relation figure can be found:

The increase in the financial performance of the cooperatives can make the cooperatives system establish or perfect the information management system conditionally, which is beneficial to the information sharing between the cooperatives and the suppliers and the vendors, and thus reduce the risk and ensure the effective promotion of the cooperatives financial performance.

\section{E. Feedback Comprehensive Analysis of Agricultural Products Supply} Chain System

"Fig. 5" shows the cause-and-effect relation diagram of farmers' specialized cooperative performance influence factors in the agricultural supply chain composed of the above four subsystems.

"Fig. 5" shows that the influence factors of cooperatives performance in the supply chain agricultural products include: regional economy, local policy, scale of cooperatives, supply chain status of cooperatives, social reputation of cooperatives; transportation management, inventory management, logistics response ability, quality of agricultural products , delivery speed, market share; relationship with suppliers, relationship with vendors; supplier information share, vendor information share, supply risk, demand risk and so on.

\section{SUGGESTIONS ON IMPROVING THE PERFORMANCE OF COOPERATIVES}

\section{A. Expand the Scale of Cooperatives Management}

Cooperatives should strive to change the traditional decentralized small-scale agricultural production mode through the horizontal or vertical integration of the supply chain, change the weak nature of traditional agriculture, and obtain scale economies. When cooperatives get scale economies, they can improve their

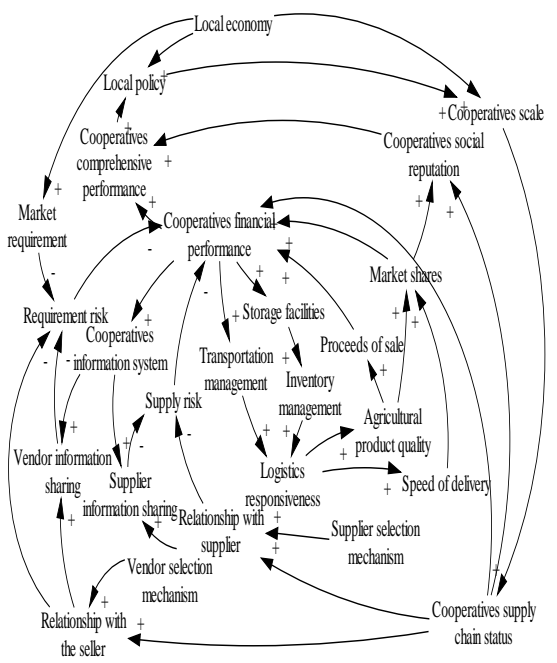

Figure 5. The causal feedback figure of agricultural supply chain system.

profitability and market competitiveness while gaining a range economies, enhancing their competitive position in the agricultural products supply chain and improving their social reputation.

\section{B. Improve the Cooperatives Agricultural Products Logistics Management Level \\ Firstly, a certain capacity of cooperatives can improve their own transport and storage facilities and equipment conditions, and apply professional technology and logistics management organization model in the agricultural products packaging, preservation, distribution processing and other aspects. Secondly, cooperatives can introduce third-party logistics enterprises to provide professional agricultural products logistics service. Through the above measures, cooperatives can enhance logistics responsiveness, shorten delivery time, ensure the quality of agricultural products, increase market share, increase sales} revenue and improve cooperatives performance.

C. Establish Close Cooperatives Partnership with the Upstream and Downstream Enterprises 
The cooperatives should maintain a good business communication with the cooperatives enterprises and gradually establish a trust relationship. Through the supply chain contract, a reasonable interest distribution mechanism among the partners should be established to improve the performance of the whole supply chain while achieving the win-win, and to ensure long-term effective operation of the partnership. In addition, a good supply chain partnership is the basis and guarantee of information share and risk share.

D. Achieve Information Share with the Upstream and Downstream Cooperatives Enterprises

The cooperatives establishing and improving the information system and achieving information sharing upstream and downstream cooperatives enterprises can reduce the market information distortion along the supply chain upward transmission process, avoid market risks, help cooperatives to develop a reasonable operational strategy, reduce production and operation costs, improve the performance of the entire supply chain and related stakeholders.

\section{SUMMARY}

This paper applies the system dynamics method to divide the agricultural products supply chain into four subsystems, and analyzes the cooperatives performance influence factors from the qualitative point of view through the cause-and-effect relation figure, and puts forward the countermeasures and suggestions. The future study needs to be determined from the quantitative point of view through further empirical research to determine the sensitivity of each factor to the performance of cooperatives, to find the best path to improve the performance of cooperatives

\section{ACKNOWLEDGMENT}

The authors wish to thank Xiangyu Guo, Zhijie Leng, Chenhuan Kou. This work was supported in part by a grant from the National Planning Office of Philosophy and Social Science of China, "The study of the performance optimization and benefit coordination mechanism of cooperatives in agricultural supply chain ", (Grant No. 13BJY105).

\section{REFERENCES}

[1] S. Z. Huang, J. Lin, and X. C. Xu, "The empirical analysis of cooperatives governance mechanism and its performance," China Rural Economy, no. 3, pp. 65-73, 2008.

[2] X. C. Xu, and Wu Bin, "Effects of governance mechanism on the performance of cooperatives-based on the empirical analysis of 526 cooperatives in Zhejiang Province," China Rural Economy, no. 5,pp. 43-55, 2010.

[3] W. H. You, X. L. Deng, and X. H. Fu, "Study on the evaluation system and profitability of social network relationship of cooperativesbased on the empirical analysis of Sichuan Province," Agricultural Technology \& Economy, no. 8, pp. 96-104, 2011.

[4] Y. F. Sun and H. P. Yu. "Study on the effect of institutional arrangement of cooperatives on members' behavior and organizational performance," The Journal of Nanjing Agricultural University (Social Science Edition), vol. 12, no. 4, pp. 61-69, 2012.

[5] D. H. Li and J. H. Chen. "Performance analysis of cooperatives-based on Jiangxi Province survey data," Agricultural Technology \& Economy, no.12, pp. 65-75, 2014.

Yongyue Liu was born in Daqing city of China in December 1979. Liu graduated from Manchester Metropolitan University in Manchester in the United Kingdom, majoring in business information technology management with a Master's degree.

$\mathrm{He}$ is the lecturer of the Heilongjiang Bayi Agricultural University of China, and to be a Doctoral candidate in the Northeast Agricultural University of China. The research interests are agricultural economy and agricultural products supply chain management.

Xiangyu Guo was born in Harbin city of China in July 1965. Guo graduated from Shenyang Agricultural University in Shenyang City of China, majoring in agricultural economic management with a Doctor's degree

$\mathrm{He}$ is the professor and doctoral supervisor of the Northeast Agricultural University of China. The research interests are agricultural economy and rural cooperatives economy. 